\title{
HLA antigens and seronegative rheumatoid arthritis
}

T BARDIN, ${ }^{1}$ L LEGRAND, ${ }^{2}$ B NAVEAU, ${ }^{1}$ A MARCELLI-BARGE, ${ }^{2}$

N DEBEYRE, ${ }^{1}$ G M LATHROP, ${ }^{3}$ J C POIRIER ${ }^{2}$ M SCHMID,

A RYCKEWAERT, ${ }^{1}$ AND A DRYLL

From the IClinique Rhumatologique de l'Hôpital Lariboisière, 6 rue Guy Patin, 75010 Paris; ${ }^{2}$ Unité $\vec{\circ}$ INSERM U 93, Hôpital Saint-Louis, Paris; ${ }^{3}$ Laboratoire d'Anthropologie Biologique, Université Paris 7, Paris

SUMMARY HLA antigens and clinical features in a series of 46 Caucasian patients (40 females, males) with definite repeatedly seronegative rheumatoid arthritis (RA) of more than two yearsi duration (mean 11.6 years) were compared with those in 77 seropositive RA patients and 116 controls of the same ethnic and geographic origin. Seronegative RA appeared to be less often? erosive than seropositive RA, and seronegative patients had fewer extra-articular features. The frequency of the HLA antigen DR1 was raised in seronegative patients as compared with controls: $(\mathrm{p}=0.006$, relative risk $=3)$ and with seropositive patients $(\mathrm{p}<0.05)$. HLA-DR4 was slightl必 increased in seronegative patients compared with controls $(p<0 \cdot 05)$ but was clearly less so than in seropositive patients $(\mathrm{p}<0 \cdot 005)$. Early onset of disease was very significantly associated witloo HLA-DR1 in seronegative patients $(\mathrm{p}=0.007)$, whereas HLA-DR4 was present more frequently in seropositive patients with onset prior to age $35(\mathrm{p}<0.05)$. No correlation between HLAD antigens and intolerances to drugs was found in seronegative patients, whereas in seropositive patients side effects to gold salts were associated with DR3. These results suggest tha杘 seropositive and seronegative RA have distinct HLA-DR associations, especially in disease oळ early onset, in addition to well established clinical differences.

Key words: HLA system, rheumatoid factor, rheumatoid arthritis, gold salts.

The association of seropositive rheumatoid arthritis (RA) with the HLA system has been well established in several ethnic groups. Seropositive RA has been repeatedly shown to be associated with the HLA antigen DR4 in Caucasians, ${ }^{1-11}$ blacks, ${ }^{11}{ }^{12}$ Latin Americans, ${ }^{1}$ and Japanese. ${ }^{13}$ In Asian Indians, according to one report, ${ }^{5}$ and in Jews ${ }^{14}$ the disease has been correlated with DR1. Only in one population, the Yakima Indians, is seropositive RA not correlated with HLA antigens. ${ }^{15}$ In contrast, studies of HLA antigens in seronegative RA have given disparate results. Some investigators have reported a high frequency of HLA-DR4 in seronegative RA, ${ }^{2} 4813$ whereas another group showed a high frequency of DR $1 .{ }^{9}$ Other studies have not shown any HLA antigen association with seronegative $\mathrm{RA}^{1}{ }^{36}$ Moreover some researchers have

Accepted for publication 10 July 1984 .

Correspondence to $\mathrm{Dr} \mathrm{T}$ Bardin, Clinique Rhumatologique, Hôpital Lariboisière, 6 rue Guy Patin, 75010 Paris, France. found an association of seronegative RA with the antigen DR4 in black patients ${ }^{12}$ but no HLA associations with the same disease in Caucasians. These discrepancies prompted us to study the HL antigen distribution in a series of 46 carefully selected patients with seronegative $\mathrm{RA}$ and to compare the antigen frequencies obtained wit those, already reported elsewhere, ${ }^{7}$ observed in $7 \overline{7}$. seropositive RA patients and 110 controls of similas ethnic and geographic origin. ${ }^{16}$ In addition clinicăb features of the disease were recorded and compare $\$$ in the two series of patients.

\section{Patients and methods}

Forty-six Caucasian patients from the Paris area were selected according to the following criteria: (18) Seronegative RA was the working diagnosis of th $\bar{\Phi}^{+}$ rheumatologist in charge of the patient. (2) RA wo definite or classical according to ARA criteria. $\frac{1}{2}$ Other seronegative arthritides were carefully ex 
cluded: in particular all patients had normal sacroiliac $x$-rays, and none had a familial history of psoriasis or ankylosing spondylitis. (3) Articular involvement was roughly symmetrical and predominantly distal. (4) Disease duration exceeded two years. (5) Search for rheumatoid factor had been repeatedly and consistently negative by two methods, namely latex F II and Waaler-Rose tests. Seronegativity was defined as latex determination $<1 / 80$ and Waaler-Rose $<1 / 40$.

All the patients were re-examined for the purpose of the study. Their clinical notes were also reviewed to assess disease duration and severity, type and tolerance of treatments, and to look for an extraarticular involvement. Schirmer and Rose Bengal tests were recorded in 27 patients' notes, and positivity of these two tests was the criterion used for diagnosis of Sjögren's syndrome. $X$-rays of the hands and wrists were taken at the time of the study and blood was drawn to perform latex and WaalerRose tests, a test for antinuclear antibodies (ANA) by indirect immunofluorescence using rat hepatocytes as a substrate, and HLA typing.

Patients were tested for 49 alleles of four HLA loci. HLA A, B, and C groups were determined by the microcytotoxicity method using peripheral blood. ${ }^{18}$ The DR specificities were determined by the standard technique described by Legrand and Dausset. $^{19}$

Unless otherwise stated, the $\chi^{2}$ test was used for statistical analysis of the results.

\section{Results}

\section{CLINICAL FINDINGS}

Clinical data in seropositive and seronegative patients are summarised in Table 1. Seronegative patients appeared to have an erosive disease less often than seropositive patients, despite similar treatment and disease duration $(p<0 \cdot 01)$. Extraarticular features of the disease were more frequent in seropositive than in seronegative patients, especially Raynaud's phenomenon, Sjögren's syndrome and rheumatoid nodules. The number of patients with at least one extra-articular feature was significantly $(p<0.01)$ higher in seropositive than in seronegative patients. Tolerance to treatments was similar in the two groups.

\section{HLA ANTIGENS}

No significant difference was found between the frequencies of HLA A, B, and C antigens among seropositive or seronegative patients and controls. In particular the antigen B27 was found in 4\% of seronegative RA patients and in respectively $8.7 \%$ and $10 \%$ of seropositive RA patients and controls.
Table 1 Clinical features in the two series of $R A$ patients

\begin{tabular}{lll}
\hline & $\begin{array}{l}\text { Seronegative } \\
\text { patients } \\
(n=46)\end{array}$ & $\begin{array}{l}\text { Seropositive } \\
\text { patients } \\
(n=77)\end{array}$ \\
\hline $\begin{array}{lll}\text { M/F ratio range } \\
\text { Age of onset (yrs) mean }\end{array}$ & $6 / 40$ & $16 / 61$ \\
Patients with erosive arthritis & $(18-72)$ & $41 \cdot 4$ \\
Raynaud's phenomenon & $32(69 \%)$ & $68(80 \%)$ \\
Rheumatoid nodules & 1 & 11 \\
Episcleritis & 0 & 6 \\
Cutaneous vasculitis & 0 & 1 \\
Neuritis multiplex & 0 & 1 \\
Seritis & 1 & 2 \\
Amyloidosis & 0 & 1 \\
Sjögren's syndrome & $5 / 27(18 \cdot 5 \%)$ & $25 / 64(39 \%)$ \\
Patients with at least one & & \\
extra-articular feature & $8(17 \cdot 4 \%)$ & $32(41 \cdot 5 \%)$ \\
Gold salt treatment & $34(74 \%)$ & $69(89 \cdot 6 \%)$ \\
D-penicillamine treatment & $16(34 \cdot 8 \%)$ & $31(40 \cdot 2 \%)$ \\
Steroid therapy & $30(65 \%)$ & $52(67 \cdot 5 \%)$ \\
Antinuclear factor & $14(30 \%)$ & $27(33 \%)$ \\
\hline
\end{tabular}

$\mathrm{p}<0.01$.

Frequencies of B7-CREG did not differ significantly in the three groups.

The HLA-DR distributions in the 46 seronegative RA patients as well as in 77 seropositive RA patients and in 110 controls are shown in Table 2 . These distributions differed in several respects. The DR1 frequency was clearly increased in seronegative RA patients as compared with controls $(p=0 \cdot 006)$, whereas this frequency appeared similar in seropositive patients and in controls. The DR4 frequency was slightly elevated in seronegative patients $\left(\chi^{2}=4 p<0.05\right)$ as compared with controls but was significantly less than in seropositive patients $(p<0.005)$. The relative risk for seronegative RA was three for the antigen DR1 and 2.4 for the antigen DR4.

Table 2 Distribution of DR antigens in seronegative and seropositive $R A$ patients and controls

\begin{tabular}{|c|c|c|c|}
\hline & $\begin{array}{l}\text { Seronegative } R A \\
\text { (46 patients) }\end{array}$ & $\begin{array}{l}\text { Seropositive } R A \\
\text { ( } 77 \text { patients) }\end{array}$ & $\begin{array}{l}\text { Controls } \\
(110)\end{array}$ \\
\hline DR1 & $15(32 \cdot 6 \%)$ & $13(16 \cdot 9 \%)$ & $15(13 \cdot 6 \%)$ \\
\hline DR2 & $11(23.9 \%)$ & $24(31 \cdot 2 \%)$ & $34(30 \cdot 9 \%)$ \\
\hline DR3 & $13(28 \cdot 2 \%)$ & $23(29.9 \%)$ & $24(21 \cdot 8 \%)$ \\
\hline DR4 & $14(30.4 \%)$ & $51(66 \cdot 2 \%)$ & $17(16 \cdot 3 \%)$ \\
\hline DR5 & $8(17 \cdot 4 \%)$ & $12(15 \cdot 6 \%)$ & $38(34 \cdot 54 \%)$ \\
\hline DR6 & $9(19 \cdot 6 \%)$ & $3(3.9 \%)$ & $15(13.63 \%)$ \\
\hline DR7 & $11(23.9 \%)$ & $9(11 \cdot 7 \%)$ & $34(30.91 \%)$ \\
\hline DR8 & 0 & 0 & $3(2 \cdot 7 \%)$ \\
\hline Blank & $11(23.9 \%)$ & $19(24 \cdot 7 \%)$ & $40(36 \cdot 3 \%)$ \\
\hline
\end{tabular}


CORRELATIONS BETWEEN CLINICAL FINDINGS AND HLA ANTIGENS

The correlation of clinical features with HLA antigens differed in the two series of patients. In seronegative RA patients early onset of disease was clearly associated with the HLA-DR1 antigen $(p=0 \cdot 007$, Wilcoxon rank test $)$. In these patients the mean age of onset was 38.47 for DR1 positive patients and 53.87 for DR1 negative patients. In contrast, in the seropositive RA patients DR4 was found most frequently when onset was prior to age $35(\mathrm{p}<0.05)$, as already reported. ${ }^{20}$ A correlation between the antigen DR3 and intolerance to gold salts (aurothiopropanol sulphonate) was found in seropositive patients and has been reported elsewhere. ${ }^{21}$ In seronegative patients 15 developed intolerance to gold salts, including four with proteinuria, 10 with cutaneous intolerance, and one with stomatitis. Only four of these patients and one of the four patients with renal intolerance were positive for DR3 antigen versus five of 19 patients who had a high tolerance for the drug. Thus adverse reactions to gold salts do not seem to be correlated with the DR3 antigen in the seronegative patients. Similarly, none of the five seronegative patients who developed adverse reactions to $\mathrm{D}$-penicillamine, including two cases of proteinuria, were DR3 positive, whereas three out of four seropositive patients with $\mathrm{D}$-penicillamine induced proteinuria were DR3 positive. ${ }^{21}$ We have also reported on the decreased frequency of DR4 antigen in seropositive RA patients with Sjögren's syndrome (SS) as compared with seropositive RA patients without SS. We were unable to test for such correlation in seronegative patients, as only five had Sjögren's syndrome. Finally, no correlations were found between HLA antigens and disease severity, extraarticular features, or ANA status in the two series of patients.

\section{Discussion}

This study has allowed us to show several clinical and immunogenetical differences between seronegative and seropositive RA. From a clinical view point the articular involvement was found to be less severe and the extra-articular features of the disease less frequent in seronegative RA patients. These findings are in agreement with those in previous studies which suggested that the articular prognosis was worse in seropositive than in seronegative $\mathrm{RA}^{22-25}$ and that extra-articular involvement, including rheumatoid nodules, vasculitis, and Sjögren's syndrome correlated with seropositivity. ${ }^{22} 2627$
In contrast, immunogenetic studies of seronega tive RA have given conflicting results. Sever. groups reported a high HLA-DR4 frequency seronegative as well as in seropositive $R$ patients, ${ }^{24813}$ whereas others claimed that DRA

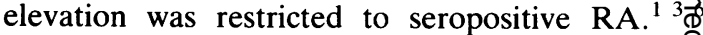
These discrepancies are possibly due in part differences in patient selection, as investigators have used different criteria for the diagnosis of seroneg tive RA. In our study particular attention was paid to selecting patients with a clinical profile suggesting RA and who were constantly seronegative by two methods, with a disease duration exceeding two years. In all cases the articular involvement was roughly symmetrical, with distal predominance, and other seronegative arthritides were careful excluded. The population of patients we studieg with seronegative rheumatoid arthritis clearly differed from seropositive patients and from cork trols. The frequency of HLA-DR4 was slight elevated in seronegative patients in comparisom with controls, but this increase is at the limit of statistical significance. In contrast the frequency of DR4 was very significantly elevated in seropositive patients as compared with controls $\left(p<10^{-9}\right)^{7}$ and with seronegative patients $(p<0 \cdot 005)$. O the other hand, the frequency of DR1 antigen was clearly elevated in seronegative patients as conf pared with controls. Interestingly we have show that DR1 is associated with a slightly increased rist for seropositive RA when the data are corrected fo the high DR4 frequency. ${ }^{7}$ Nevertheless, DR1 is significantly more frequent in seronegative patients as compared with seropositive patients $(\mathrm{p}<0.05)$.

DR1 has been previously reported to be elevate in seropositive RA in Jewish populations ${ }^{14}$ and Asian Indians, ${ }^{5}$ but to the best of our knowledge mention has been made of its frequency in seronegঞ tive RA patients of these ethnic groups. In Cauca sians the frequency of DR1 has been found to b? elevated in seronegative RA in one study undep taken by Swiss investigators. ${ }^{9}$ Our results als suggest that DR1 is associated with seronegative $R \bar{A}$ in Caucasians. The correlation we found between DR1 and an early onset of seronegative RA supports the hypothesis of a susceptibility fact@b associated with this antigen.

Finally, we were unable to demonstrate and association between HLA antigens and intolerance्e to drugs in our series of seronegative RA patient? Several groups, ${ }^{28-30}$ including ours, ${ }^{21}$ have reporteळ an increased risk for intolerance to gold salts $\overline{\mathscr{Q}}$ D-penicillamine treatments in seropositive RA p tients carrying the DR3 antigen, but we do not kno of other such studies in seronegative RA patientsOur results suggest that the association of DR3 with 
adverse effects to gold salts and D-penicillamine treatments may be restricted to seropositive RA.

\section{References}

1 Stasny P. Joint report on rheumatoid arthritis. In: Terasaki P I, ed. Histocompatibility testing. Los Angeles: 1980: 681-6.

2 Panayi G S, Wooley P, Batchelor J R. Genetic basis of rheumatoid disease HLA antigens: disease manifestations and toxic reactions to drugs. $\mathrm{Br}$ Med J 1978; ii: 1326-8.

3 Dobloug J H, Forre O, Kass E, Thorsby E. HLA antigens and rheumatoid arthritis. Association between HLA-DRw4 positivity and IgM rheumatoid factor production. Arthritis Rheum 1980; 23: 309-13.

4 Gran J T, Husby G, Thorsby E. The association between rheumatoid arthritis and the HLA antigen DR4. Ann Rheum Dis 1983; 42: 292-6.

5 Woodrow J C, Nichol F E, Zaphiropoulos G. DR antigens and rheumatoid arthritis: a study of two populations. $\mathrm{Br}$ Med J 1981; 283: 1287-8.

6 Alarcon G S, Koopman W J, Acton R T, Barger B O. Seronegative rheumatoid arthritis. A distinct immunogenetic disease? Arthritis Rheum 1982; 25: 502-7.

7 Legrand L, Lathrop G M, Marcelli Barge A, et al. HLA DR genotypes in seropositive rheumatoid arthritis. Am J Hum Genet 1984; 36: 690-9.

8 Scherak O, Smolen J S, Mayr W R. HLA DR antigens and disease patterns of rheumatoid arthritis. Rheumatol lnt 1983; 3: 113-6.

9 Swiss federal commission for the rheumatic diseases. HLA DR antigens in rheumatoid arthritis. Rheumatol Int 1981; 1: 111-3.

10 Jaraquemada, Pachoula-Papasteriadis C, Festenstein H, Sachs J A, Roit I M, Corbett M, Ansell B. HLA D and DR determinants in rheumatoid arthritis. Transplant Proc 1979; 11: 1306.

11 Karr R W, Rodey G E, Lee T, Schwartz B D. Association of HLA DRw4 with rheumatoid arthritis in black and white patients. Arthritis Rheum 1980; 23: 1241-5.

12 Alarcon G S, Koopman W J, Acton R T, Barger B O. DR antigen distribution in blacks with rheumatoid arthritis. $J$ Rheumatol 1983; 10: 579-83.

13 Maeda H, Juji T, Mitsui H, Sonozaki H, Ohitsu K. HLA DR4 and rheumatoid arthritis in Japanese people. Ann Rheum Dis 1981; 40: 299-302.

14 Schiff B, Mizrachi Y, Orgad S, Yaron M, Gazit E. Association of HLA Aw31 and HLA DR1 with adult rheumatoid arthritis. Ann Rheum Dis 1982; 41: 403-4.

15 Wilkens R F, Hansen J A, Mulmgren J A, Nisperos B,
Mickelson E M, Watson M A. HLA antigens in Yakhima indians with rheumatoid arthritis. Arthritis Rheum 1982; 25: 1435-9.

16 Bardin T, Dryll A, Naveau B, et al. HLA DR antigens differentiate seronegative from seropositive rheumatoid arthritis in early onset disease (abstract) Arthritis Rheum in press.

17 Ropes M W, Bennett G A, Jacox C S, Jessar R A. 1958 revision of diagnostic criteria for rheumatoid arthritis. Bull Rheum Dis 1958; 9: 175-6.

18 Mittal K K, Mickey M R, Singal D P, Terasaki P I. Refinement of microdoplet lymphocyte cytotoxicity test. Transplantation 1968; 6: 913-27.

19 Legrand L, Dausset J. A second lymphocyte system (Ly Li). Histocompatibility testing. Copenhagen: Munksgaard, 1975: 665-70.

20 Bardin T, Dryll A, Debeyre N, Ryckewaert A. Polyarthrite rhumatoïde et système HLA. Recherche d'une corrélation entre les antigènes d'histocompatibilité et les caractéristiques de la maladie. Nouv Presse Med 1982; 11: 2753-6.

21 Bardin T, Dryll A, Debeyre N, et al. HLA system and side effects of gold salts and D-penicillamine treatment of rheumatoid arthritis. Ann Rheum Dis 1982; 41: 599-601.

22 Cats A, Hazevoet H M. Significance of positive tests for rheumatoid factor in the prognosis of rheumatoid arthritis. Ann Rheum Dis 1970; 29: 254-60.

23 Duthie J J R, Brown P E, Truelove L H, Baragar F D, Lawrie A J. Course and prognosis in rheumatoid arthritis: a further report. Ann Rheum Dis 1964; 23: 193-204.

24 Edelman J, Russel A S. A comparison of patients with seropositive and seronegative RA. Rheumatol Int 1983; 1: 47-8.

25 Ragan C, Farrington E. The clinical features of rheumatoid arthritis. JAMA 1962; 181: 663-7.

26 Gordon D A, Stein J L, Broder I. The extraarticular features of rheumatoid arthritis. A systematic analysis of 127 cases. $\mathrm{Am} \mathrm{J}$ Med 1973; 54: 445-52.

27 Bardin T, Dryll A, Debeyre N, Peltier A P, Ryckewaert A. Les polyarthrites rhumatoïdes avec anticorps antinculéaires. Nouv Press Med 1982; 11: 501-4.

28 Wooley P H, Griffin B J, Panayi G S, Batchelor J R, Welsh K I, Gibson T J. HLA DR antigens and toxic reactions to sodium aurothiomalate and D-penicillamine in patients with rheumatoid arthritis. $N$ Engl J Med 1980; 303: 300-2.

29 Gran J T, Husby G, Thorsby E. HLA DR antigens and gold toxicity. Ann Rheum Dis 1983; 42: 63-6.

30 Speerstra F, Reebers P, Van de Putte L B, Vandenbroucke J P, Rasher J J, de Rooij D J. HLA DR antigens and proteinuria induced by aurothioglucose and D-penicillamine in patients with rheumatoid arthritis. J Rheumatol 1983; 10: 948-53. 